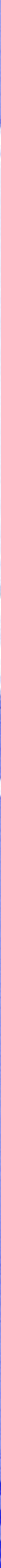




\title{
ENTRE CONTOS E RECONTOS NOS RECANTOS DA ARTE LITERÁRIA
}

\author{
ENTREVISTA COM RICARDO AZEVEDO
}

TALES AND RETALES IN CHILDREN'S LITERATURE

INTERVIEW WITH RICARDO AZEVEDO

Marcelita Negrão Trindade Vilela'

\author{
André Luiz Ming Garcia²
}

1 Mestre em Letras (Estudos Comparados de Literaturas de Língua Portuguesa) pela Universidade de São Paulo, onde atualmente cursa doutorado pelo mesmo programa.

2 Doutor, mestre, licenciado e bacharel em Letras (Língua e Literatura Alemã) pela Universidade de São Paulo, onde atualmente é professor colaborador e realiza estágio pós-doutoral. 
Em nossos dias, diversos escritores multiplicam suas invenções e permitem que muitas crianças conheçam, mediante a fruição das suas obras, a riqueza da arte literária. A produção literária infantil e juvenil continua, pois, em expansão, assim como (cons) ciente da importância da fabulação e do jogo na vida de cada ser humano, sobretudo das crianças. Por isso, consiste em especial oportunidade para interessados em arte e literatura conhecer o trabalho de escritores que, com muito humor, misturam o imaginário com o real, as ilustrações com as palavras, a literatura com a cultura popular e fundem os sonhos das crianças com suas próprias vidas, assim como o faz Ricardo Azevedo.

Ricardo José Duff Azevedo é paulista, ilustrador e escritor da literatura infantil e juvenil brasileira, nascido em 1949. Filho de Aroldo de Azevedo e de Maria Gertrudes Duff Azevedo, é casado e tem três filhos. Formou-se em Comunicação Visual pela Fundação Armando Álvares Penteado (FAAP) e é doutor em Letras pela Universidade de São Paulo.

Escreveu seu primeiro texto infantil, Um Autor de Contos para Crianças, aos 17 anos, o qual, 13 anos mais tarde, viria a tornar-se Um Homem no Sótão. A partir de 1980, após o lançamento de O peixe que podia cantar, publica mais de 100 títulos para crianças e adolescentes, entre poesia, prosa e contos populares. Suas obras mais recentes são Trago na boca a memória do meu fim (Editora Ática, 2019), O livro das casas (Editora Moderna, 2015) e Caderno veloz de anotações, poemas e desenhos (Melhoramentos, 2015). A trajetória literária de Ricardo Azevedo tem início em 1980 com a publicação do livro O peixe que podia cantar. Situa-se, deste modo, entre os escritores que abordam os problemas da sociedade contemporânea por meio de uma linguagem inovadora. Suas produções contribuíram, assim, para o panorama da literatura infantil e juvenil através de sucessivas publicações que foram reconhecidas com premiações que atestam o grande valor literário de seus livros.

Atualmente, Ricardo Azevedo possui inúmeras obras infantis e juvenis publicadas, e é considerado um dos mais significativos escritores do gênero, com uma abrangência de títulos que inclui narrativas em prosa e em verso, sempre em constantes reedições, assim como também conquistou diversos prêmios literários, entre eles o da Associação Paulista de Críticos de Arte (APCA), com Pobre corinthiano careca 
(1995), e ganhou várias vezes o prêmio Jabuti: Teoria e crítica literária com Abençoado e danado do samba - Um estudo sobre o discurso popular, Edusp, $20142^{\circ}$; Juvenil com Fragosas brenhas do mataréu (Editora Ática, 2014); Infantil com Dezenove poemas desengonçados (Editora Ática, 1999); Juvenil com Maria Gomes (Editora Scipione, 1991); Infantil com Alguma coisa (Editora FTD, 1989). Além de premiações, tem livros publicados na Alemanha, Portugal, México e Holanda.

Desde 1980, Ricardo Azevedo pesquisa contos maravilhosos, adivinhas, quadras, anedotas, ditados e frases feitas do Brasil todo para recontá-las a seu modo, o que resultou em várias antologias sobre a cultura popular. Ricardo Azevedo é um escritor que podemos considerar de múltiplas faces, pois, além da produção literária infantil e juvenil, destaca-se, também, como pesquisador. Observamos, contudo, a escassez de estudos críticos sobre a vasta produção do escritor em questão. Há artigos que resultam em comunicações em universidades renomadas do país, tais como a dissertação de mestrado intitulada Entre traços e letras: Um estudo introdutório sobre a produção literária de Ricardo Azevedo (2005), de Penha Lucilda de Souza Silvestre, apresentada à Universidade Estadual de Maringá (UEM).

De acordo com Silvestre (2005), os livros de Ricardo Azevedo dedicados à literatura infantil e juvenil revelam uma proposta inovadora tanto pela linguagem como pela estruturação da narrativa. Destacam-se obras como Um homem no sótão (1982), Nossa rua tem um problema (1993), Aviãozinho de papel (1994), Uma velhinha de óculos, chinelos e vestido azul de bolinhas brancas (1998), Trezentos parafusos a menos (2002) e Zé Pedro e seus dois amores e outras histórias (Ática, 2015). Cada obra realça uma tendência peculiar do escritor para enfatizar diferentes temas, valores e pontos de vista.

Na literatura infantil e juvenil, há uma profusão tanto de textos realistas, por um lado, quanto de obras mais fantasistas, por outro, bem como de narrativas que se encontram em um imbricamento de ambas as tendências. Ricardo Azevedo apropria-se do híbrido, tanto no que se refere à construção e focalização dos personagens, como à estrutura organizacional do texto. A ficção de Azevedo, desse modo, não está apenas voltada para aquilo que se pode viver na realidade, mas alcança, também, o mundo da fantasia e do sonho, em um equilíbrio coerente e harmônico. 
Quanto aos personagens criados pelo escritor, há a variação desde animais, como aqueles que perpassam também as diversas faixas etárias (crianças, adolescentes, adultos), até objetos. Tanto quando os protagonistas são animais quanto quando se trata de objetos, esses compartilham do mesmo espaço que os seres humanos. Sua produção literária não está focada no moralismo, pois seus personagens assumem diferentes opiniões que levam a diferentes verdades.

O narrador, por sua vez, narra os fatos sob diferentes óticas. Podemos perceber que esse fato representa uma inovação no campo da literatura infantil e juvenil contemporânea, pois rompe com características tradicionais a partir do emprego da linguagem coloquial, o que permite aproximar o leitor de seu texto.

Ricardo Azevedo apresenta também destaque na produção de contos folclóricos, organiza um trabalho diversificado sobre a cultura popular e visita em suas obras os diversos gêneros da literatura oral, que já renderam uma série de vários livros, como Contos de espanto e alumbramento (Scipione, 2005), Bazar do folclore (2001) e Histórias que o povo conta (2002), publicados apenas pelo governo; No meio da noite escura tem um pé de maravilha! (2000) e O moço que carregou o morto nas costas e outros contos populares (2015).

Para o escritor, a literatura infantil tem suas raízes nas formas literárias populares. Por isso, é expressivo o seu interesse pelo tema. As contribuições de Ricardo Azevedo, no campo folclórico, com pesquisas de contos populares que resultam em novas versões dos textos, recontadas de acordo com sua visão, geraram comentários, elogios e pesquisas de alguns estudiosos.

Já na poesia, Ricardo Azevedo aborda temáticas que partem da realidade, do cotidiano e do universo da criança, mas que também dão margem à fantasia e à imaginação. Sua produção poética é composta das seguintes obras: Dezenove poemas desengonçados (1998); A casa de meu avô (1998); Meu material escolar (2000); O livro de papel (2001); Não existe dor gostosa (2003); Ninguém sabe o que é um poema (2005); O livro das casas (2015); Feito bala perdida e outros poemas (2007) e Caderno veloz de anotações, poemas e desenhos (2015).

Juntamente com a construção poética, encontra-se a ilustração que enriquece as obras, por meio da linguagem visual, provocando dinamicidade dos movimentos e 
sendo responsável pela coesão e completude do poema. No que se refere à ilustração, trata-se de outro importante elemento na organização da narrativa, pois dialoga e complementa o texto verbal. Como já mencionado, Ricardo Azevedo destaca-se também entre diversos profissionais que vêm desenvolvendo ilustrações nos livros infantis.

Apresentamos, até o presente momento, aspectos da inovação que Ricardo Azevedo trouxe à literatura para as crianças. Resta, ainda, ressaltar que, em meio a essa sua identidade artística plural de escritor e ilustrador, destaca-se, também, um Ricardo Azevedo estudioso, pesquisador da cultura popular e crítico.

A importância da leitura e da formação do leitor é um dos assuntos que também preocupam Ricardo Azevedo. Em meio a tantos outros pesquisadores e críticos, ele se desponta como um estudioso preocupado com questões como a literatura na escola, o livro de imagem e a influência da cultura popular na literatura infantil.

Desde o início da década de 1990, Azevedo publica artigos em jornais e revistas especializadas, como também textos em livros voltados para a formação do leitor. Nota-se, dessa forma, que Ricardo Azevedo vem publicando e desenvolvendo diversos estudos, quer seja através de palestras, artigos, seminários em congressos de leitura e literatura, quer seja mediante a realização de pesquisas científicas, como a que deu origem à sua dissertação de mestrado e à que resultou em sua tese de doutorado. Inevitável não considerar sua contribuição aos estudos literários e, principalmente, não perceber que sua produção teórica dialoga com sua produção literária.

Após esta breve retrospectiva sobre sua obra, encontra-se, a seguir, a entrevista que nos foi gentilmente concedida pelo autor via e-mail. 
1. Após a leitura de alguns de seus livros, notamos a importância da pesquisa que o senhor realiza sobre a cultura popular, quer seja na coleta de histórias folclóricas, quer seja na escrita de suas próprias versões. 0 que lhe motivou a realizar pesquisas como essas? $O$ senhor já considerou em um de seus artigos que os contos folclóricos podem ser a introdução para o mundo literário? Se sim, devido a quais de suas características e de que forma?

Quando comecei a escrever pensando na chamada literatura infantil, imediatamente me vieram à cabeça os contos populares (maravilhosos, de fadas ou de encantamento, lembrando que nem todos têm fadas e encantamentos) e as quadras populares. Tinha um bom conhecimento desse material e uma imensa admiração. Ficava pensando: falam em literatura "para crianças" mas indicam a leitura de "Branca de Neve" (no conto, a mãe, quando percebe que a filha virou mulher, manda matá-la) ou “João e Maria" (abandonados na floresta pelo próprio pai) ou Pedro Malasartes ( um herói cheio de ardis e com uma ética duvidosa: trata-se do trickster). Na verdade, esses contos nunca foram exclusivamente para crianças, são contos populares, expressam valores populares e se destinam a todos nós, daí o "populares". Fora isso, costumam ser metáforas, versões simbólicas e intuitivas das coisas que mais tememos e daquilo que mais buscamos. Como autor iniciante, esse material parecia indicar que meus limites podiam ser bem mais ricos e amplos.

Um outro ponto foi quanto à linguagem. Falavam em "linguagem para crianças" e eu me perguntava: como assim? o que seria exatamente isso?

Minha sensação hoje é a de que escrever para crianças e jovens tem pouco a ver com esse público específico. Para mim significa principalmente escrever usando uma linguagem popular, clara, pública e compartilhável. Acabei até fazendo um estudo sobre o "discurso popular" na tentativa de tentar compreendê-lo melhor. 


\section{Como o senhor considera o tratamento que a literatura infan-} til recebe na escola atualmente? Esse tratamento aproxima ou distancia a criança deste mundo literário?

Falando de um modo geral, sinto que muitos professores tratam os livros de literatura como um mero auxiliar dos livros didáticos. Inclusive passam aos alunos a ideia de que o livro lido tem sempre uma lição ou uma mensagem a ser aprendida. Confundem, em outras palavras, livros didáticos com livros de literatura. Resultado: o estudante pega o livro já preocupado se vai descobrir a lição ou não.

Tudo indica que esses professores não são leitores e desconhecem o que são a ficção e a poesia. Pensam que todos os livros são necessariamente prescritivos e utilitários. Imagine ler Carlos Drummond de Andrade ou Guimarães Rosa ou Lygia Bojunga ou Ziraldo procurando que lições o autor tentou passar! Livros didáticos pretendem que 100\% dos leitores tenham uma mesma e única interpretação. A literatura e a arte não funcionam assim. Simplesmente porque elas são ficção, abordam assuntos de forma subjetiva, podem reinventar a linguagem, podem recorrer a metáforas e, enfim, trazem visões pessoais e singulares (não oficiais) a respeito de eventos humanos. Como não são leitores, muitos professores parecem desconhecer isso. Pena.

2b) Dando continuidade à questão anterior, o que lhe parece, como escritor e como pesquisador, do lugar relegado à literatura infantil e juvenil no meio acadêmico brasileiro e no seio dos estudos literários de forma geral?

Sei de muitos professores e grupos de estudos, pelo Brasil inteiro, voltados ao estudo sistemático da literatura infantil e juvenil, gente competente que tem produzido trabalhos muito bons. Mas sinto que são bolhas de estudos acadêmicos. Não acho que essa produção atinja quem deveria atingir: o imenso contingente de professores que, é preciso que se diga, em geral vive em condições precárias, às vezes não têm dinheiro para comprar livros, nem tempo para estudar. 
3. Hoje há diversos projetos de leitura realizados nas escolas. Na sua opinião, o que um bom projeto de leitura deve privilegiar?

Não sou professor. Minha sensação é a de que se a escola conseguir fazer com que seus alunos saibam diferenciar o que é ciência e tecnologia do que é arte e literatura, já vai ser uma maravilha. Infelizmente muitas escolas se satisfazem em passar aos alunos a ideia de que tudo o que interessa é aquilo que pode ser mensurado e controlado. Ou apenas aquilo que é utilitário. Trata-se de um baita equívoco. Assuntos como as paixões humanas, a busca do autoconhecimento, as iniciações, a injustiça, a humilhação, a morte, as contradições, as ambiguidades ou, como dizia Richard Rorty, os assuntos ligados "às formas privadas de lidar com nossa finitude" - e que interessam a todas as pessoas independentemente de classes sociais, graus de instrução e faixas de idade - em geral são solenemente ignorados pela escola. Isso sem falar que a linguagem da literatura e da arte pode e deve ser subjetiva, inventiva e poética, ao contrário do livro técnico que tende à linguagem objetiva e oficial. Imagine um estudante sair da escola sem saber diferenciar a linguagem técnica da linguagem poética! No fundo, como sabemos, boa parte das escolas busca apenas formar técnicos consumidores acríticos. Trata-se de um modelo escolar que desumaniza. É triste. Num país como o nosso, mais triste ainda.

\section{Quanto à questão da divulgação dos contos folclóricos na sala} de aula, o que poderia ser feito para que tivéssemos uma maior divulgação da cultura popular como forma de reconhecimento e valorização?

Numa síntese, vejo dois modelos de consciência interagindo na sociedade. Um é o do sistema cultural dominante, individualista, tecnológico, escolarizado, moderno e hegemônico. O outro é o modelo popular, altamente diversificado e construído espontaneamente por meio da oralidade. Este tende a ser tradicional, valoriza a pessoa situada numa rede hierárquica e familiar, é marcado pela religiosidade, valoriza o contexto onde se vive e a 
experiência prática (não téorica). Ambos representam padrões sociais, culturais, éticos e estéticos diferentes. Se para os alunos das classes médias e altas, filhos de pais alfabetizados e especializados, o discurso da escola parece fazer sentido, para os alunos oriundos da tradição oral - a grande maioria da população brasileira - ele apresenta um caráter autoritário, preconceituoso e excludente. Esses alunos de certa forma são levados a desprezar tudo que são, seus pais, seus avós, suas tradições, crenças, costumes e estilo de vida, afinal seus parentes "não sabem nada": não sabem ler nem escrever e desconhecem a gramática, as ciências, a matemática, a História etc. Caramba! Essas pessoas têm uma rica cultura popular! E os contos, os ditados, as quadras, as anedotas, a iconografia, as danças, músicas e ritmos populares? Quando esse aluno tem a sorte de, na escola, entrar em contato com um conto de encantamento, uma quadra, um trava-língua ou um dito popular, o cara abre a boca espantado: "Peraí! Mas meus pais conhecem isso! Isso eu já ouvi! Meu avô contava essa história! Isso faz sentido pra mim!". Hoje, essa mesma criança costuma ser levada a envergonhar-se de si mesma e de seus próprios pais, que desconhecem tudo o que a escola ensina. É como vejo.

\section{Separar ficção da realidade é uma preocupação que o escritor de}

livros infantis deve ter? Existem cuidados para escrever uma história infantil?

Duvido que alguém de fato consiga separar a realidade da ficção. Isso é um mito redutivo demais! A gente só consegue ver as coisas tendo por base nossa experiência de vida, nossa cultura, nossas crenças e, inclusive, nossos interesses. Outras pessoas partem de outras bases e veem outras coisas. De forma não programada, creio que meus textos refletem um pouco essa ideia. Ao longo da vida, fui constatando que um dos assuntos mais recorrentes nos meus livros, embora de forma não intencional, é a existência ou convivência de diferentes pontos de vista válidos sobre um mesmo assunto. Isso aparece desde o meu primeiro livro O peixe que podia cantar, lançado em 1980, e continua claramente em Um homem no sótão, O leão Adamastor, O livro das 
palavras, Motoqueiro que virou bicho, O livro dos pontos de vista, Trezentos parafusos a menos, O chute que a bola levou, Fragosas brenhas do mataréu e, pensando bem, em todos os meus livros. A discussão da existência de diferentes pontos de vista válidos sobre um mesmo assunto, na minha visão, deveria ser feita inclusive dentro das escolas. $\mathrm{O}$ fanatismo e o totalitarismo nascem da ideia contrária: a existência de um único ponto de vista válido sobre os assuntos. Se queremos construir e viver numa sociedade democrática e civilizada, é preciso aprender a conviver com a divergência desde pequeno. Independentemente de qualquer coisa, esse assunto me toca e me motiva muito.

6. Como já enfatizava Ligia Cademartori nos anos 1980, literatura infantil (e juvenil) é literatura antes de que a esse termo seja acrescentado o adjetivo "infantil". Apesar disso, é consenso que a LIJ apresenta diversas especificidades, muitas delas determinadas pelo direcionamento intencional que é feito ao público infantil ou juvenil. Da sua parte, enquanto autor, como se manifesta essa intencionalidade de endereçamento? De modo mais intuitivo, mais racional? Quais decisões estéticas norteariam a definição desses direcionamentos? E, por fim, para o senhor, como autor, ao endereçar seus textos a crianças ou a adolescentes, considera que existam ou deva haver diferenças entre as obras direcionadas a cada um desses públicos?

Do meu ponto de vista, a literatura lembra uma frondosa árvore cheia de galhos e esses galhos representam diferentes literaturas, todas legítimas e todas irmãs, pois são fruto de um mesmo tronco.

As chamadas literaturas para crianças e jovens são galhos dessa mesma e única árvore onde florescem as outras literaturas. As formas literárias populares, contos, quadras etc. também.

Qual o ponto comum entre esses galhos? O caráter estético da obra literária e na verdade de toda obra de arte. 
Tento dizer que, antes de mais nada, a literatura e a arte, sejam adulta, infantil, juvenil ou popular, tanto faz, devem ter certas características que são de caráter estético e não ideológico ou pertencente a alguma escola literária. Coisas como sua originalidade; sua capacidade ficcional (e a ficção é uma forma extraordinária de experimentar a verdade); recursos como a metáfora (o texto diz uma coisa, mas parece querer dizer outra); o menor uso possível de estereótipos e fórmulas prontas; a exploração inventiva e consciente da linguagem; a linguagem marcada pela subjetividade; a abordagem de temas humanos complexos (chamo de "assuntos que ninguém sabe" porque não podem ser ensinados. Por exemplo, a busca do autoconhecimento; as paixões; as contradições e as ambiguidades humanas; as angústias, a construção da própria voz, a colisão entre as idealizações e a realidade, a morte, etc).

As obras literárias certamente costumam ser impregnadas de ideologias e crenças, nem teria como ser diferente pois cada autor tem sua visão de mundo, sua ideologia e suas crenças. Mas a relevância e a qualidade da obra não vêm daí. Este é o ponto.

Além disso, para mim, como autor, é mil vezes mais estimulante que a literatura trabalhe não com as diferenças - sempre ocasionais e provisórias - mas com as semelhanças entre todas as pessoas e aborde assuntos que possam criar identificações entre crianças, jovens e adultos.

7. As discussões sobre LIJ, levando em conta a questão dos endereçamentos, sempre suscitam reflexões a respeito do que seria ou não apropriado a crianças e jovens. Essa dita apropriação dependeria de múltiplos fatores e variaria, naturalmente, com o passar do tempo e com as mudanças na sociedade e no entendimento de infância e de adolescência. Qual foi sua motivação para incluir, em Contos de espanto e alumbramento, temáticas tão contemporâneas e transgressoras e polêmicas como paixões e sombras da psique humana, rompendo com certa linearidade e planicidade observadas em certa parte das obras endereçadas aos pequenos leitores? 
Preciso dizer que, quando era adolescente, ainda não existia uma "literatura juvenil". Passei dos livros "para crianças" para os livros adultos que tínhamos em casa, claro, os que eu conseguia ler. Isso foi ótimo! Certamente ampliou minha consciência e me ajudou a compreender melhor as coisas da vida e do mundo. Livros com versões de narrativas populares como Contos de Espanto e Alumbramento e $O$ moço que carregou o morto nas costas e outros contos populares, assim como livros totalmente criados por mim, como O motoqueiro que virou bicho, Fragosas brenhas do mataréu e Trago na boca a memória do meu fim, são livros que eu imagino que vão ser lidos por leitores jovens ou adultos, seja pelos assuntos que tratam, seja pela linguagem mais complexa, particularmente os dois últimos nos quais tentei arremedar uma linguagem próxima à que se usava nos tempos coloniais. Mas os dois primeiros, compostos de versões de contos populares, creio que podem ser lidos também pelos leitores menores que conseguirem.

8. Geralmente, o artista cria e os estudiosos avaliam, criticam, analisam sua obra. Apesar disso, cada vez mais vemos surgir artistas-pesquisadores. Embora estes últimos normalmente não procedam à avaliação das próprias obras, sempre é de nosso interesse, enquanto leitores e aficionados, saber do próprio autor: De qual de suas obras se orgulha mais e por quê? Alguns autores reescrevem ou reilustram suas próprias obras algum tempo depois com vistas a aperfeiçoá-las ou atualizá-las. Há alguma criação sua que gostaria de modificar? Por quê?

Se bobear, todas certamente têm alguma coisa que poderia mexer para melhorar. O que posso dizer é que acho importante, primeiro, diferenciar os livros inteiramente criados por mim daqueles que escrevi a partir da cultura popular. Há também os livros Fragosas brenhas do mataréu e Trago na boca a memória do meu fim, que me demandaram uma pesquisa de muitos anos sobre o período colonial brasileiro e sua rica linguagem. Me orgulho de ter conseguido escrever esses livros. Fora isso, há a questão da ilustração. 
Tanto sou escritor como sou desenhista. Ambas as áreas me expressam totalmente, me apresentam questões que me interessam muito - a metáfora é uma delas - , me desafiam com os diversos recursos que apresentam e que preciso aprender a usar, enfim, me sinto privilegiado por poder escrever e por poder desenhar.

Correndo por fora, tem meu Abençoado e danado do samba - Um estudo sobre o discurso popular, publicado pela Edusp, e do qual também tenho muito orgulho. Fiz o estudo principalmente para mim mesmo, na tentativa de compreender ou pelo menos me posicionar diante de um monte de questões.

9. Muito se teoriza e reflete sobre as especificidades das linguagens verbal e visual. Por um lado, trata-se de códigos que se valem de suas especificidades para expressar melhor algum tipo de mensagem poética. No livro ilustrado, porém, se imbricam e complementam. Como autor tanto de textos verbais quanto visuais, e de narrativas híbridas que integram ambos os códigos, qual é a sua visão a respeito? O que o verbal faz melhor que o visual, o que o visual oferece que supera o que o verbal ofereceria na mesma situação? Qual o papel das ilustrações nos seus livros? Como elas nascem?

Quando ilustro, a ideia ou a tentativa é a de que as imagens que crio não repitam o que o texto diz, mas acrescentem elementos ou forneçam uma metáfora do que o texto disse. Quando o leitor lê o texto e vê a imagem, meu desejo é que surja um terceiro significado composto da soma do texto com a imagem e diferente dos dois vistos de forma isolada. Em O livro das casas, composto de pequenos poemas e imagens, isso fica explícito. Por exemplo, o texto diz: "A pulga vive feliz/ Pois é um bicho de sorte/ Sua casa tem comida/ E é seu meio de transporte”. A ilustração mostra um cachorro em cima de um sofá.

Um outro ponto pra mim fascinante, como já disse, é o uso de metáforas. Quando falo em metáfora penso, claro, em alguma transposição de 
sentido que diga uma coisa, embora pareça dizer outra. Mas que essa transferência de significado busque um acervo inesperado ou mesmo ilógico, tenha caráter singular, ambíguo e subjetivo e nunca permita uma chave única de leitura. $\mathrm{O}$ fato de um texto inteiro corresponder a uma metáfora é, penso eu, o que costuma dar a ele a possibilidade de oferecer ao leitor diversas leituras e interpretações dentro, claro, de um certo contorno significativo. A simples gratuidade em princípio está fora deste contorno. No caso do desenho, a metáfora tende naturalmente a ser mais direta, crua e concisa, mas tanto nos textos como nos desenhos trata-se de um recurso fundamental. Você consegue imaginar um manual técnico ou um livro didático escrito e ilustrado por meio de metáforas?

10. Cada vez mais novas mídias e tecnologias estão presentes no cotidiano de crianças e jovens. Isso tornou mais difícil atrair as crianças para o universo da leitura? A literatura precisa se adaptar? As tecnologias podem ser vilãs, de algum modo, ou podem ser aliadas? Por quê?

Difícil responder a essa questão. Meu palpite é que talvez essas tecnologias façam com que as pessoas passem a ler de forma diferente da que se lia quando a leitura era basicamente feita a partir do texto impresso. Não sei. Mas se o leitor estiver interessado e a fim de se aprofundar num determinado tema, disposto a ler pra valer e usufruir plenamente do texto de forma a ampliar sua consciência sobre o tal assunto, não tem jeito, vai ter que se concentrar e gastar energia seja qual for o suporte. Para mim, a leitura do livro de forma isolada e num ambiente adequado é melhor para a fruição do texto do que ler na tela de computadores, iPads etc. Mas talvez seja uma mera questão de hábito.

11. Seu primeiro livro foi publicado em 1980. O que mudou em sua forma de criar de lá para cá? Sua forma de escrever é a mesma?

Naturalmente, creio que hoje escrevo e desenho melhor e nem po- 
deria ser diferente. Trabalho com livros há quarenta anos e isso me deu alguma experiência. Mas, confesso, parece que cada novo texto exige que eu aprenda a como escrevê-lo e, fora isso, como disse, certos interesses meus continuam recorrentes de forma não programática até hoje. Talvez o maior prazer de escrever ou desenhar seja o aprendizado que surge sempre a cada novo trabalho.

12. Quanto ao livro Contos de Enganar a Morte, é interessante o trabalho que realiza ao colocar a morte sob a ótica do riso. Como o senhor considera o tratamento que o tema da morte recebe na literatura independente? Como o senhor vê essa questão?

Todos nós estamos, literalmente, vivendo às voltas com as tais "formas privadas de lidar com nossa finitude", como ensinou Rorty. Velhos, moços, crianças, pobres, ricos, doutores, analfabetos, patrões, empregados, todos nós. Isso é óbvio e qualquer criança de sete anos já se deu conta disso faz tempo. Neste livro o que fiz, a partir de uma pesquisa, foi trazer versões de contos populares que tratam de heróis que tentam ludibriar ou adiar a morte. Não os vejo tanto pela ótica do riso, mas sim pela ótica do ardil. Ressalto que essas narrativas, originariamente, nunca foram exclusivamente "para crianças", mas sim para todo mundo. Por isso, são contos populares.

13. Seus livros são muito lidos pelos estudantes e seu nome é amplamente conhecido na sala de aula. Ao criar um livro, nasce um elo entre autor e leitor, leitores em formação. Isso gera uma certa responsabilidade? Qual seria o seu maior desafio?

Acho que a arte e a literatura devem, por meio da ficção, da metáfora, da linguagem inventiva e da voz singular de cada autor, falar sempre a verdade e jamais serem prescritivas, objetivas ou utilitárias.

14. A literatura infantil e juvenil contemporânea se caracteriza 
por uma série de rupturas com a tradição que se manifestam nas formas, nos motivos, nos temas, na linguagem. Entende-se que, na primeira metade do século passado, coube a Monteiro Lobato inaugurar e prever várias dessas mudanças. Muitos autores contemporâneos da LIJ brasileira foram influenciados por Lobato. É o seu caso? Qual a sua opinião sobre a obra do escritor taubateense e como você encara as recentes polêmicas ao redor de suas obras?

Creio que toda a literatura tende a romper ou questionar as tradições. Faz parte da pretensão de tentar ser minimamente original e inventivo. Não posso dizer que na infância fui um grande leitor de Lobato, mas li alguns livros dele: lembro de Caçadas de Pedrinho, O saci e principalmente Os Doze Trabalhos de Hércules, que eu li mais de uma vez e adorei. Um livro pouco lembrado é sua versão de Robin Hood. Li também mais de uma vez e gostei muito. Tenho meu exemplar até hoje. Quanto às polêmicas, se vocês se referem ao pretenso "racismo", francamente acho uma besteira. No mínimo as menções a negros, se for o caso, podem servir para abrir uma discussão com as crianças sobre o assunto. Talvez as pessoas que falam nisso sejam elas mesmas racistas e fiquem assustadas quando o assunto aparece com clareza. Acreditar que alguém possa se tornar racista por ler Monteiro Lobato, só se for uma piada. O racismo no Brasil está entranhado na sociedade e não vai ser com o "politicamente correto" que nos livraremos dele, mas sim com uma Educação de qualidade, capaz de discuti-lo e colocar os argumentos e as informações na mesa.

15. Há algum livro ou autor que marcou sua vida e, quem sabe, sua obra? De que modo também se descobriu como escritor?

Percebi que gostava de escrever fazendo as redações escolares, isso ainda no tempo do antigo ginásio, hoje, lá pela sexta série do Fundamental II. Tirava boas notas e aquilo tudo foi estimulante para mim. Ao mesmo tempo, ainda adolescente, tive contato com os textos para crianças do poeta suíço 
Peter Bichsel. Li três contos deste autor na revista Humboldt, de intercâmbio Brasil-Alemanha, que meu pai recebia. Pensei comigo: "Quero escrever que nem esse cara!". A partir da leitura dos contos de Bichsel, escrevi o texto "Um autor de contos para crianças", publicado uns treze anos depois, em 1982, pela Melhoramentos com o título de Um homem no sótão. Foi meu quarto livro, ganhou prêmios e hoje é publicado pela Ática.

Preciso contar que, ainda na infância, tive uma aproximação com a literatura muito interessante e inesperada. Na década de 50, foram lançados discos de poesia, salvo engano pela gravadora Festa, alguns com atores e outros com os próprios poetas declamando seus poemas. Um grupo de quatro atores, os Jograis de São Paulo, fez discos antológicos. Tínhamos alguns deles em casa e meu pai e minha mãe adoravam ouvir. Na época eu devia ter meus oito ou nove anos e escutava também. Meu primeiro encontro com a poesia dos extraordinários Manuel Bandeira, Carlos Drummond de Andrade, Murilo Mendes e Vinícius de Moraes deu-se através desses discos. Escutar “José”, “O caso do vestido" e "A morte do leiteiro" na voz do próprio Drummond; "Estrela da manhã" e "Vou me embora pra Pasárgada" com Manuel Bandeira, o belíssimo e surreal “Jandira”, de Murilo Mendes, ou “Dia da Criação” de Vinícius de Moraes declamados pelos maravilhosos Jograis foi uma experiência inesquecível e fundamental pra mim. Acho que percebi ali a força que um texto pode ter. Vale notar que eram todos discursos narrativos e que utilizavam vocabulário público. Mesmo assim, naquela época, eu não teria a menor competência para ler esses poemas. Mas escutar é outra história. [grifos do entrevistado] 